\title{
A Study on the Innovation of Evaluation Mechanism for Administrative Examination and Approval Based on the Customer Satisfaction
}

\author{
Shuyang Ou ${ }^{1}$, Zhouqin Tan ${ }^{1}$ \\ ${ }^{1}$ School of Political Science and Public Management, Southwest University, Chongqing, China \\ Correspondence:ShuyangOu, Associate Professor, School of Political Science and Public Management, \\ Southwest University, 400715 Tiansheng Rd\#2, Beibei Region, Chongqing, China.E-mail: \\ 13637769886@163.com.
}

\begin{abstract}
Administrative examination and approval is one of the most important management tools for government to govern the economy and society effectively. And by evaluating the efficiency of government's administrative examination and approval service and the satisfaction level of clients, we can not only improve the governance capacity of government, but also promote the transformation process of governments' functions. Based on the theory of "people-oriented" and mass line, this paper attempts to construct an evaluation system of government's administrative examination and approval based on the dimension of customer satisfaction. A discussion on the operational process and relative points for attention is also conducted.
\end{abstract}

Keywords: administrative examination and approval, customer satisfaction, evaluation mechanism.

\section{Introduction}

The existing studies on the reform of government approval system and the transformationof government functions has not been conducted from the perspective of clients' evaluation. In practice, we mainly make quantitative assessment within the government, paying much less attention to the customers' subjective feelings and their degree of satisfaction. This paper argues that we should comprehensively evaluate the governments' administrative examination and approval system in a multi-angle and multidimensional way, taking the satisfaction degree of customers as a basic guide.

\section{Research Methodology}

The evaluation of customer satisfaction can help to analyze the enterprise's market competitiveness and competitive advantages, to improve the quality of both products and services to maximize the benefit. At some point, the administrative examination and approval service can be regarded as a public product provided by the government, and the public can be considered as government customers. Public satisfaction (or customer satisfaction) refers to the satisfaction of governent's customers with the government's work, and it mainly focus on the measurement of the public's subjective perception and acceptance. 


\section{Discussion}

3.1. Customer Satisfaction: The Value Orientation of the Evaluation System for AdministrativeExamination and Approval

\section{Service}

To meet public satisfaction has always been the guiding ideology of Communist Party of China. Since citizens is the ultimate consumers of public administration and public services conducted by governments, they are the best qualified to evaluate the work of government. Since the end of 2004, China's Local Government Performance Evaluation Center of Lanzhou University leaded by Mr. Bao Guoxian had evaluated the work performance of 14 cities of Gansu province and 39 departments directly controlled by the provincialgovernmentinanorganized and systematic way. This is the first time that the government performance is evaluated by a thirdpartyorganization instead of governments itself, and the concept of "customer-tendency" is also introduced in this evaluation work.

In the process of the work performance evaluation (WPE) for governments, governments at all levels in China are also trying to explore a new-type valuation approach taking the public satisfaction as value orientation. Such as the activity called "Public Appraise the Governments' Work" which is engaged by the Nanjing Municipal
Government; and "the activity to select satisfied and unsatisfied units in the public mind" held by the Hangzhou Municipal Government. All these innovations emphasize on the important role of customer satisfaction in the work performance evaluation for governments.

\section{2. The Evaluation Index System}

Customer satisfaction of the government administrative examination and approval service is a evaluation indicator to reflect the customer's subjective experience of the administrative examination and approval affair and its quality during a certain period of time. Those contents which can't be reflected in quantitative indicators could be assessed in this way, so the evaluation of customer satisfaction has many advantages in some ways, such as insightful, comprehensive, and humanity.

Whether the evaluation index system is scientifically and reasonably designed is undoubtedly the key factor to the scientificity of the evaluation work. To construct the evaluation index system based on client satisfaction, there are two basic principles to be followed: one is comprehensiveness and globality, which means the indicators should include all aspects of the serviceobject's experience and feelings while accepting the administrative examination and approval service; the other one is to be 
proportional, which means different indexes should account different proportions in the whole evaluation, and indicators reflecting the factors customers concern most or impressed them deeply should be given a larger proportion.
According to the above two principles, this paper attempts to build a evaluation index system of administrative examination and approval service based on the customer satisfaction as shown in table one.

Table 1. The Evaluation Index System of Administrative Examination and Approval Service Based on the Customer Satisfaction

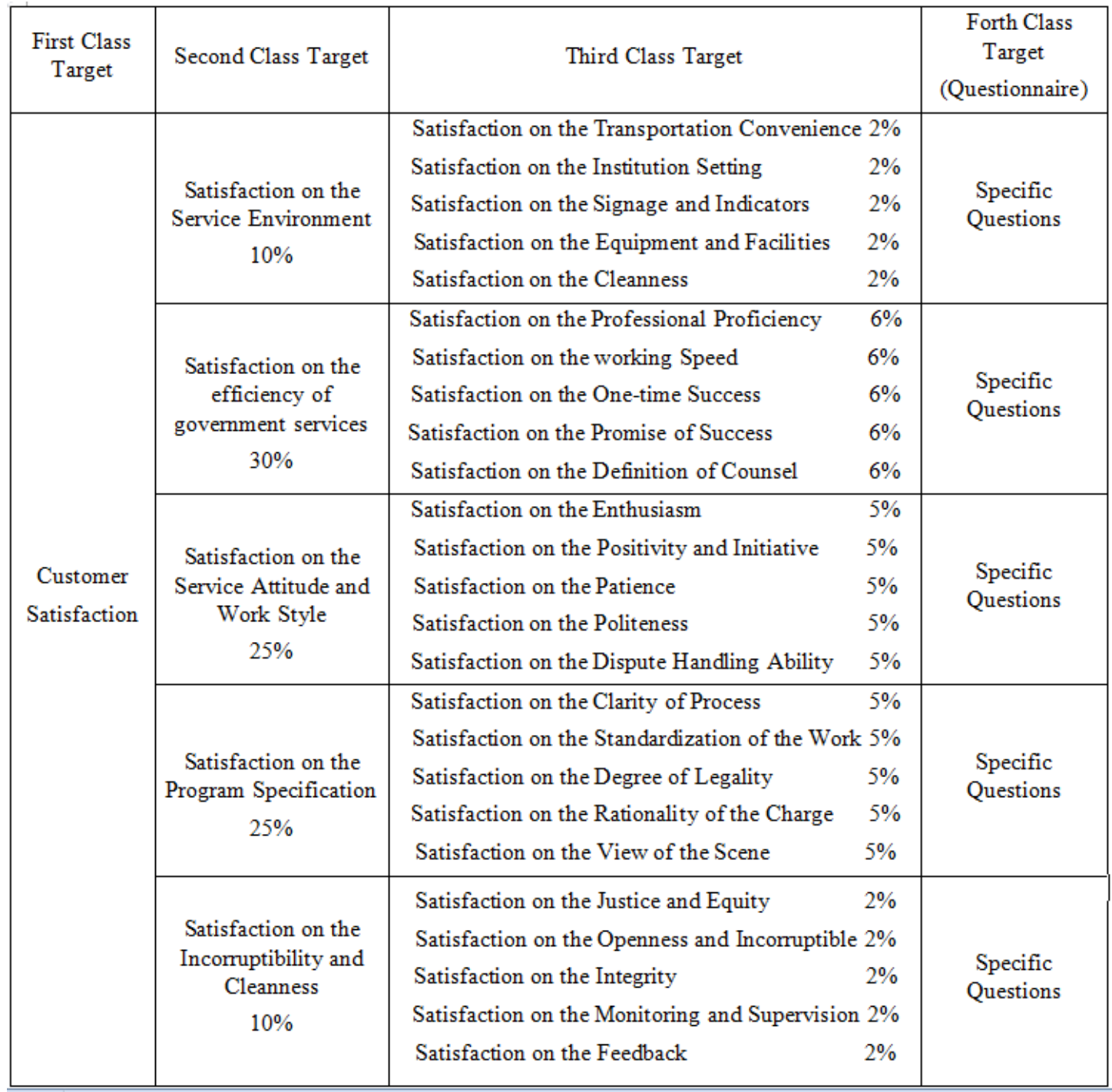

Some notes on the table above:

\subsubsection{The Design Concept of Indicators}

The indicators selected in the table above are screened from more than fifty indicators, which are designed based on the analysis of 2,000 questionnaires and more than ten thousand-word in-depth interviewing materials. Since the 
research was conducted among the administrative examination and approval departments and thousands of service customers, the indicators in table one have get their permission. The evaluation index system includes both quantitative and subjective satisfaction ones, and the index system above is only part of the overall evaluation system. In actual operation, the weight of objective and quantitative indexes can be $60 \%$, with the weight of subjective satisfaction indexes to be $40 \%$. Considering the various actual situations and the feasibility of operation, the proposed sample size of subjective satisfaction survey should be around 1000 .

\subsubsection{The Selection of Indicators}

The customer satisfaction is the primary index in the index system designed in this paper. The second-class targets have five aspects in total, which contains main matters needed to be evaluated by the customer and those related to the government approval work. The third-class targets have twenty-five measurable indicators, taking the customers' personal experiences to the processes and results of the government administrative examination and approval service as the assessment criteria. The third class target almost covers all the matters about the administrative examination and approval behavior, and the forth class target could be appropriately adjusted according to the actual situation.

\subsubsection{The Enactment of the Index Weight}

We could use the subjectively weight method to determine the weight of indexes. The professionals who designs the Customer Satisfaction questionnaire should enact different weights for different targets depending on different survey samples. Whether enacting the index weight or not and how to set the weights when we conduct a customer satisfaction survey should be decided by the specialists.

\subsubsection{The Evaluation Method to Indicators}

Since the customer satisfaction is a kind of subjective feeling, which is not suitable for quantitative evaluation, we can only use some qualitative scales to evaluate the degree of customer's satisfaction to the government's service. For each specific indicator in the questionnaire, we should choose the following five dimensions to evaluate them: "very satisfied", "satisfied", "generally satisfied", "dissatisfied", and "very dissatisfied".

\subsection{The Innovation of Evaluation Process}

To innovate the evaluation mechanism for administrative examination and approval based on the customer satisfaction requires careful organization and arrangements, and whether the evaluation process can take the customer's 
satisfaction survey as the core is the key to the success. The evaluation process for the administrative examination and approval service should include the following four basic identified stages: the initiate and preparation phase, the operation designing phase, the implementation of evaluation phase, and the feedback phase, as shown in figure one.

Figure One. The Evaluation Process for the Government's Administrative Examination and Approval Service Based on Customer Satisfaction

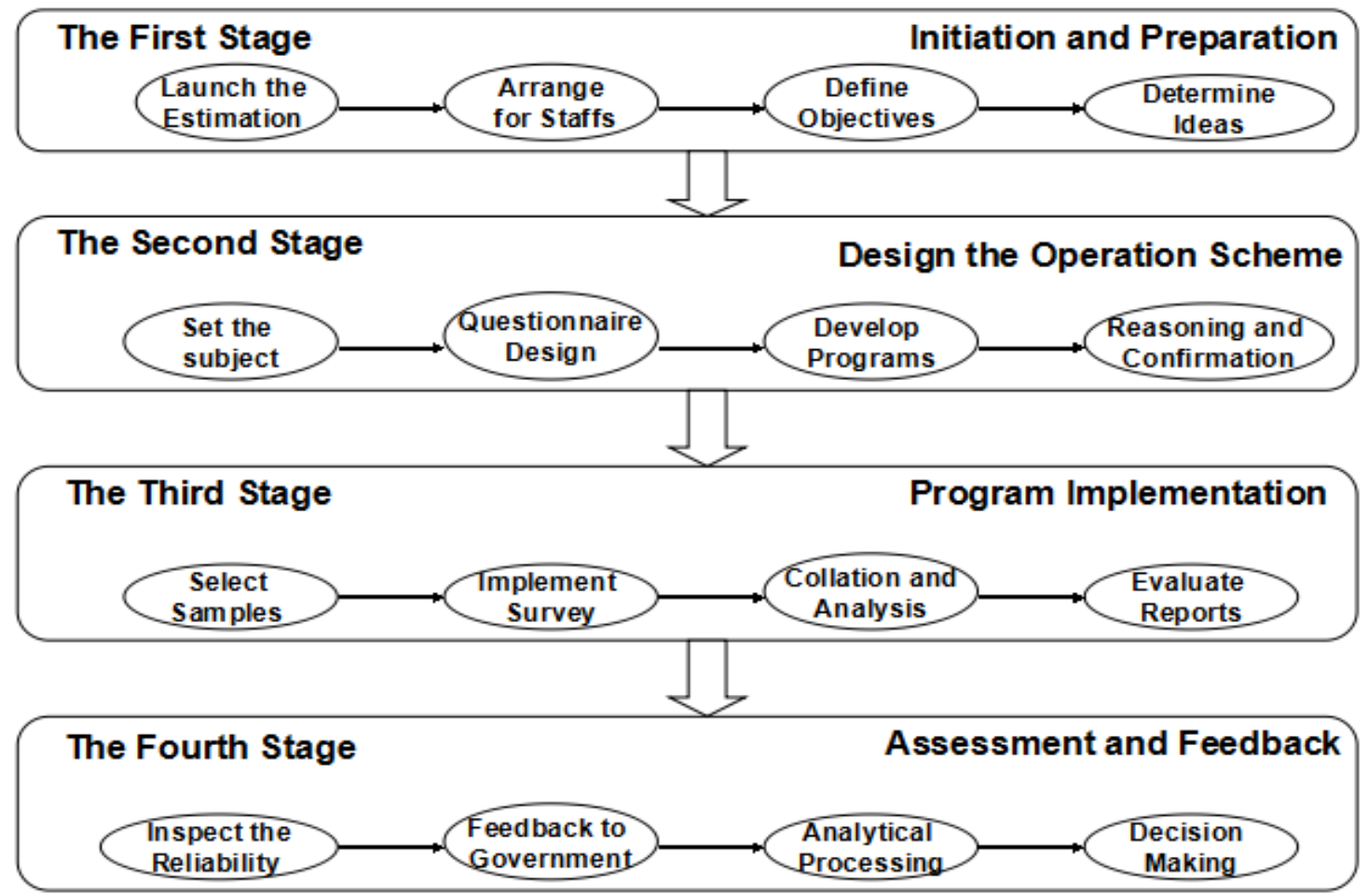


In the initiate and preparation phase, the main job is to clear the method to initiate evaluation and make necessary preparation. This paper argues that the evaluation work for governments' administrative examination and approval service should be initiated by unofficial professional research institutions or pollsters instead of the government itself. Though this way, we can make the results of assessment more objective and impartial, and it will beconduciveto culture the public's concept to question the governments' work too.

In the operation designing phase, the main task is to design the entire implementation plan. One of the most important tasks is to design the questionnaire, which has a great influence on the achievement of the evaluation objectives and the authenticity and accuracy of evaluation results.

In the implementation phase of evaluation, what we mainly have to do is carrying out a specific customer satisfaction survey. Since the survey sample's appropriateness will directly influence the credibility of evaluation results, it's very important to drawn the survey sample correctly,and the survey sample should be comprehensive and representative.

In the feedback stage, one of the most important tasks is checking the objectivity and impartiality of evaluation results. Another important task is to give an instant feedback to the government's decisionmaking departments, so that we can use the evaluation results to supervise the reasonableness of matters that require government approval and the scientificity of the approval process.

\subsection{Several Issues Required Attentions in the} Evaluation Work

To evaluate the quality of administrative examination and approval service through customer satisfaction survey is a new attempt in China, so we should pay attention to the following issues while conducting the evaluation work.

\subsubsection{Try to Avoid the Evaluation Work Being} Led and Implemented Only by the Government

If the evaluation work were single-handedly carried out by the government, it would easily be of official color and lacking of credibility. So we should actively promote the independent research institutions, pollsters or other "third party" social intermediary organizations to initiate and implement the evaluation work to ensure the evaluation work to be objective, fair, impartial, and effective.

\subsubsection{Enacting Consummate Auxiliary Laws and Regulations}

Since the function of administrative examination and approval is in a strong and monopoly position, it is almost impossible for normal service objects to estimate the service level, service attitude and efficiency of the government departments and agency workers without the guarantee of corresponding laws. As we all know any evaluation of the government's work must be conducted under the criterion and guarantee of corresponding laws and regulations, so we should enact consummate auxiliary laws and regulations to guarantee the evaluation work to be carried out successfully.

\subsubsection{To Educate the Civil Rights' Awareness to} Supervise the Administrative Approval Work

Affected by the concept of "bureaucracy and ideological" for a long time in China, the public are used to rely on the government. In order to implement the evaluation work of government's examination and approval service based on customer satisfaction, we need to break the block of this concept and cultivate the citizens' value to question and supervise the government. Only when we start to question the government, we can make the 
administrative examination and approval behavior of the government to be transparent, and make it possible for the masses to evaluate the government's approval behavior.

3.4.4. Pay More Attention to the Feedback and Application of Evaluation Results in DecisionMaking

Public's trust and support to the government depends on the degree of their satisfaction to the government's work. Only when the government timely and comprehensively tracked the evaluation results, they could have a comprehensive and correct understanding about the quality of its work and whether it conforms to the public's will or not, so it is very important to establish a feedback mechanism of the evaluation results to improve the government administrative approval service work.

\subsubsection{To Form a Full Understanding of the} Limitations

We should exhaustively understand the limitations of the evaluation method studied in this paper, because almost every evaluation method inevitably has certain limitations. The evaluation of the administrative examination and approval service is based on the subjective feeling of service objects, which is closely related to the service object's complex mental activities such as subjective psychological expectation, psychological satisfaction and personal emotional mood and so on. Since the human psychological activities are complex, sundry and uncertain, so the evaluation results got from this method exists some deviation exists a certain deviation.

\section{Conclusion}

In summary, this article insists that evaluations based on the customer satisfaction is only one dimension of the whole evaluation work for government's administrative examination and approval service. Although the evaluation from the perspective of customer satisfaction is of self-evident importance, it can't be the sole judgment to evaluate the government's administrative examination and approval service. We need to combine this kind of evaluation with quantitative indicators to form the fundamental basis of the whole evaluation work to get an authentic, comprehensive and accurate evaluation result of the government's administrative examination and approval service.

\section{Bibliography}

(1) Bao Guoxian, Sun Jiaxian. (2006). Analysis on the "Customer-Oriented" Principle of Government Performance Evaluation. Chinese Public Administration, 1, 29-32.

(2) $\mathrm{Xu}$ Jialiang. (2006). Government Evaluation Theory. Beijing: China Social Sciences Press.

(3) Liu Zhiguang. (2009). Reconstruction of 2horizontal and 2-vertical Procedure: A New Area of Administrative Examine and Approve Reformation. Chinese Public Administration, 10. 48-51.

(4) He Zhengfei, Wen Hong. (2012). Innovative the Administrative Mechanisms, and Build the Service-oriented Government. Chinese Public Administration, 4,124-12

(5) Song Shiming, Zhao Zijian. (2013). The Surface Phenomena and Substance of the State Council's Seventh Administrative Reform, Administration Reform, 4, 16-20.

(6) Li Tao. (2012). The Breakthrough Strategies of China's Administrative System Reform, Administrative Tribune, 6. 68-70. 